\title{
DESIGN OF HYBRID ENERGY STORAGE FOR PHOTOVOLTAIC POWER FLUCTUATION SMOOTHING BASED ON FREQUENCY ANALYSIS
}

\author{
LI Lin ${ }^{1, a}$, RUIRUI Yang ${ }^{1, b}$ and DAVID Yu ${ }^{2, c}$ \\ ${ }^{1}$ State Key Laboratory of Power Transmission Equipment \& System Security and New Technology, \\ Chongqing University, Chongqing 400030, China \\ ${ }^{2}$ Department of Electrical Engineering and Computer Science, University of Wisconsin-Milwaukee, \\ Milwaukee, Wisconsin 53211, USA \\ alinli@cqu.edu.com, bctyrr@163.com , cyu@uwm.edu
}

Keywords: PV system, hybrid energy storage system, fluctuation smoothing, frequency analysis Abstract. A proper design of energy storage system (ESS) can effectively smooth the photovoltaic (PV) output power fluctuation, lower the cost, as well as improve power quality and stability. According to the response characteristics of different energy storage equipment, in this paper, a hybrid ESS is applied to make better use of each energy storage (ES) capacity and lower system cost. A sizing method of battery and supercapacitor is proposed based on frequency analysis. Fast Fourier transform (FFT) method is applied for analyzing the spectrum of balancing power, dividing the compensation frequency band for each ES device, and filtering. Then the power capacity and energy capacity of each ES can be determined by conducting inverse FFT within certain frequency range. Through the proposed method, the least cost ESS solution will be determined to smooth out the PV output fluctuation under a worst case scenario.

\section{Introduction}

A hybrid ESS is an effective solution to smooth power fluctuation caused by the intermittent nature of wind and solar power. For short-term (seconds) power management, the most commonly used storage techniques in a PV system are supercapacitors like electric double-layer capacitors (EDLC). For long-term to long term (minutes to hours) power management, lead-acid batteries and lithium batteries are most widely used [1,2].

Currently, the industry typically applies a single ES device at the PV location in order to smooth PV output power fluctuation. This approach tends to oversize the ES and increase system cost. By properly integrating different types and sizes of ESS, such as lead acid battery and EDLC, the fluctuation of PV output power can be effectively smoothed. Since each ES device is of different charging and discharging speed and characteristics [3], the performance can be enhanced with less cost when operating together.

In this paper, a FFT approach to determine the optimal combination of different types of ESS is proposed. The proposed algorithm can also be applied to reduce the intermittency caused by wind power.

\section{Balancing Power}

The all-year PV output power data in 2015 is collected from an experimental station in Milwaukee in a 15-hour interval (5:00 a.m.- 8:00 p.m.) every day. A worst case is selected to design the ESS. Accepted power in the grid is calculated based on existing grid input power fluctuation standards [4] as shown in Table 1.

According to the standard, the maximum fluctuation of grid input power is $0.2 \mathrm{MW}$ per minute in the station. Since sampling time in this paper is 1 second, to simplify the standard, we assume the maximum fluctuation for 1 second is $1 / 60$ of the value for 1 minute, which is about $3 \mathrm{~kW}$. 
Table 1. Grid input power fluctuation limitation

\begin{tabular}{ccc}
\hline PV station type & $\begin{array}{c}\text { Maximum power } \\
\text { variation in 10min (MW) }\end{array}$ & $\begin{array}{c}\text { Maximum power variation } \\
\text { in 1 min (MW) }\end{array}$ \\
\hline Small & Installed capacity & 0.2 \\
Medium & Installed capacity & Installed capacity/5 \\
Large & Installed capacity/3 & Installed capacity/10 \\
\hline
\end{tabular}

Based on this limitation, the notion of system balancing was developed and is used universally in all systems. According to reference [5], balancing represents excess or shortage capacity in the system, either in the form of excess available generation or shortage demand in PV. Balancing power is the key factor to sizing ES capacities.

Based on PV output power $P_{a}$, grid acceptable power $P_{a}$, the balancing power $P_{b}$ can be expressed as follows:

$$
P_{b}=P_{o}-P_{a} .
$$

Balancing power $P_{3}$ as shown in Fig. 1 is the power required to be smoothed by ESS under the selected worst case scenario when PV system is operating.
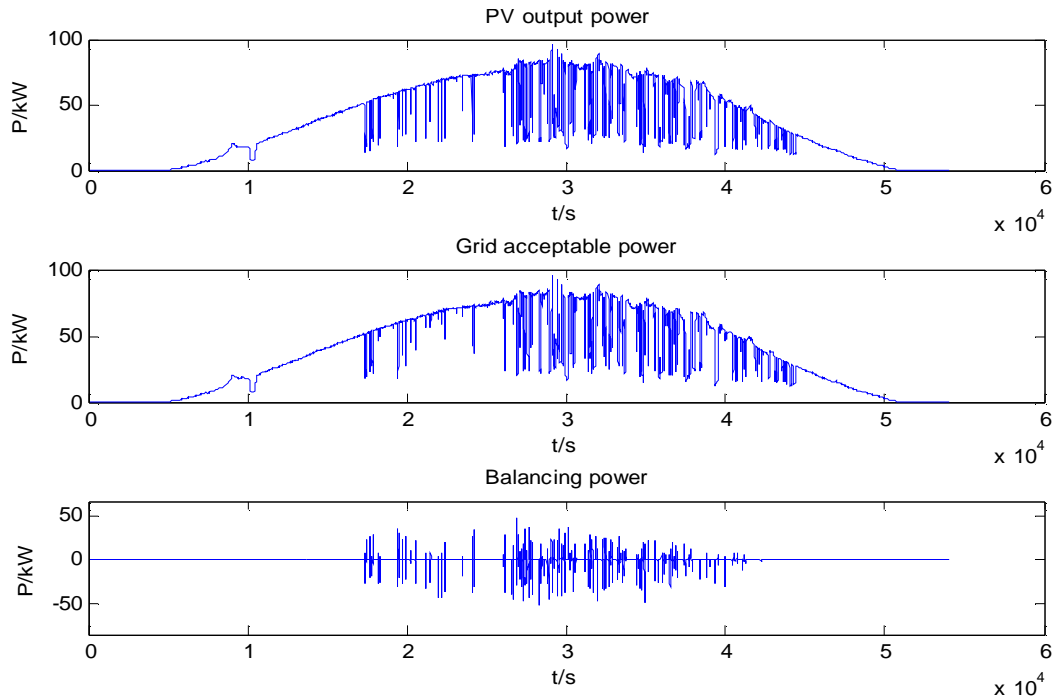

Fig. 1. Balancing power of the worst case

In the balancing power figure,

$\boldsymbol{P}_{b}>0$ : PV generates excess available power which need to be absorbed by ESS. ES is charging.

$\boldsymbol{P}_{b}<0$ : PV generates insufficient available power which need to be supplied by ESS. ES is discharging.

\section{Proposed Method}

FFT Method. Different technologies are suited for operation over different time periods. The balancing power, shown in Fig. 1 can be broken down into the components spanning different frequency ranges. This decomposition can be achieved by using FFT. Each component of the periodic signal, except for the zero frequency component, represents cycling energy that averages to zero over each cycle [5].

FFT analysis equation:

$$
X[f]=\sum_{t=0}^{N-1} x[t] W_{N}^{t f}, f=0, \ldots, N-1 .
$$

Inverse Fourier transform (iFFT) synthesis equation: 


$$
x[t]=\frac{1}{N} \sum_{f=0}^{N-1} X[f] W_{N}^{-t f}, f=0, \ldots, N-1
$$

where $\mathrm{N}$ is the number of the data points in the sequence:

$$
\begin{aligned}
& (x[0], x[1], \ldots, x[N-1]) . \\
& W_{N}^{t f}=e^{-j(2 \pi / N) t f} .
\end{aligned}
$$

FFT method is conducted to the balancing power in the worst case to convert balancing power from time domain into frequency domain as shown in Fig. 2.
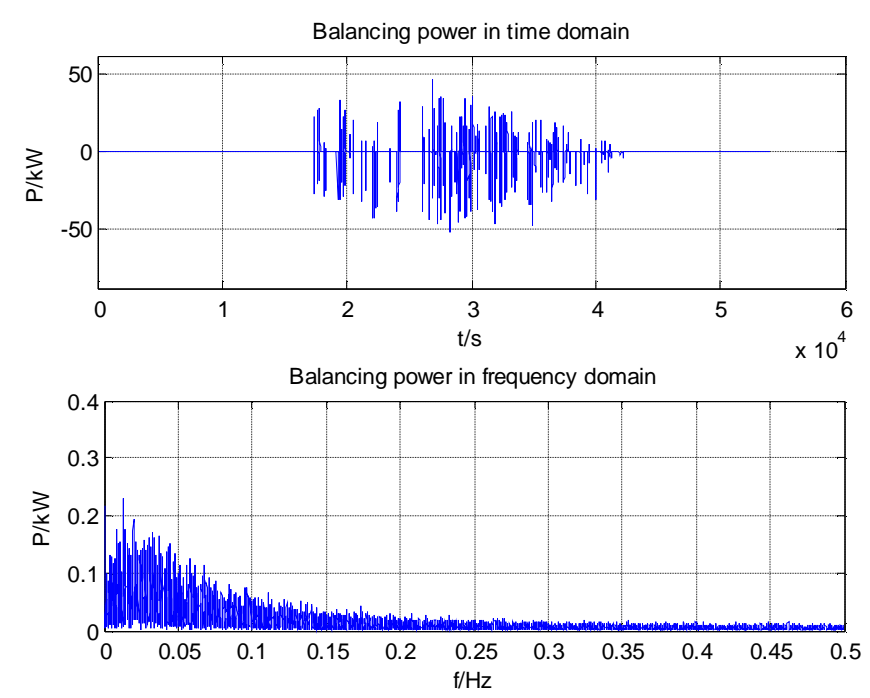

Fig. 2. Balancing power in time domain and frequency domain

It can be seen that the spectrum of balancing power mainly concentrates on the low frequency bands. The low frequency balancing powers, which contain a DC component, are of high amplitudes. However, because of the existence of high frequency powers, even though their amplitudes is relatively low, when only apply one ES in the system, to smooth out these high frequency fluctuations, its power capacity will be oversized a lot, thus total cost will increase.

ES Types and Cutoff point. Based on the response characteristic of each battery, three kinds of ESS, which are most commonly used: lead acid battery, lithium ion battery and EDLC are researched. According to literature [6-9], information of each ES is listed in Table 2.

Table 2. ESS information

\begin{tabular}{ccccc}
\hline \multirow{2}{*}{ ESS type } & \multirow{2}{*}{$\begin{array}{c}\text { Shortest } \\
\text { response time }\end{array}$} & Maximum response & \multicolumn{2}{c}{ Unit cost } \\
\cline { 4 - 5 } & frequency $(\mathrm{Hz})$ & $\mathrm{P}(\$ / \mathrm{kW})$ & $\mathrm{E}(\$ / \mathrm{kWh})$ \\
\hline Lead acid & $2(\mathrm{~min})$ & $8.33 \times 10^{-3}$ & 200 & 100 \\
Lithium & $1(\mathrm{~min})$ & 0.0167 & 500 & 300 \\
EDLC & $1(\mathrm{~s})$ & 1.00 & 150 & 4000 \\
\hline
\end{tabular}

Lead acid and lithium battery have a relatively long response time, but their cost is low. They are able to track power variations, ranging from minutes to several hours, which are corresponding to the low frequency powers. The response rate of EDLC is very fast, it is able to response dynamic fluctuations and is well suitable for the compensation of the high frequency components. The power amplitudes of high frequency components are relatively low and will not lead to a large ES capacity.

Cutoff points are the dividing frequencies of different ESs. Also, they represent the cutoff frequencies of low pass filters when determine ES capacities. In this paper, based on the objective to combine long-term ES and short-term ES together to lower cost, two combinations of three kinds ES are analyzed: lead acid battery and EDLC with cutoff point moving from $0 \mathrm{~Hz}$ to $8.33 \times 10-3 \mathrm{~Hz}$, lithium ion battery and EDLC with cutoff point moving from $0 \mathrm{~Hz}$ to $0.0167 \mathrm{~Hz}$. 
ES capacities. To calculate the capacity of each ES, FFT filtering is conducted by keeping the frequency band corresponding to the response frequency of each ES and setting the signal amplitude of the other one as zero. For lead acid battery, a low pass filter can be set to clean power within $[8.33 \times 10-3 \mathrm{~Hz}, 0.5 \mathrm{~Hz}]$ while keep power within $[0 \mathrm{~Hz}, 8.33 \times 10-3 \mathrm{~Hz}]$. For EDLC, a high pass filter can be set to clean power within $[0 \mathrm{~Hz}, 8.33 \times 10-3 \mathrm{~Hz}]$ while keep power left.

Then invers FFT method is conducted to covert the function after filtering into time domain with only one certain frequency power. To make sure this designed ESS is able to smooth out power fluctuations in all frequency bands, the power capacity of each ES is determined based on the peak value (maximum or minimum) in time domain.

Then the integration of balancing power in each frequency band is conducted to calculate the energy capacity of each battery with certain frequency. Considering 50\% state of charge (SOC) [10], the energy capacity for each ES will be twice of the peak value (maximum or minimum) in energy curve.

\section{Optimal System Design}

In order to find out the system minimum total cost and its corresponding ES capacities, ES capacities of both power and energy under different cutoff points are calculated as shown in Fig. 3.
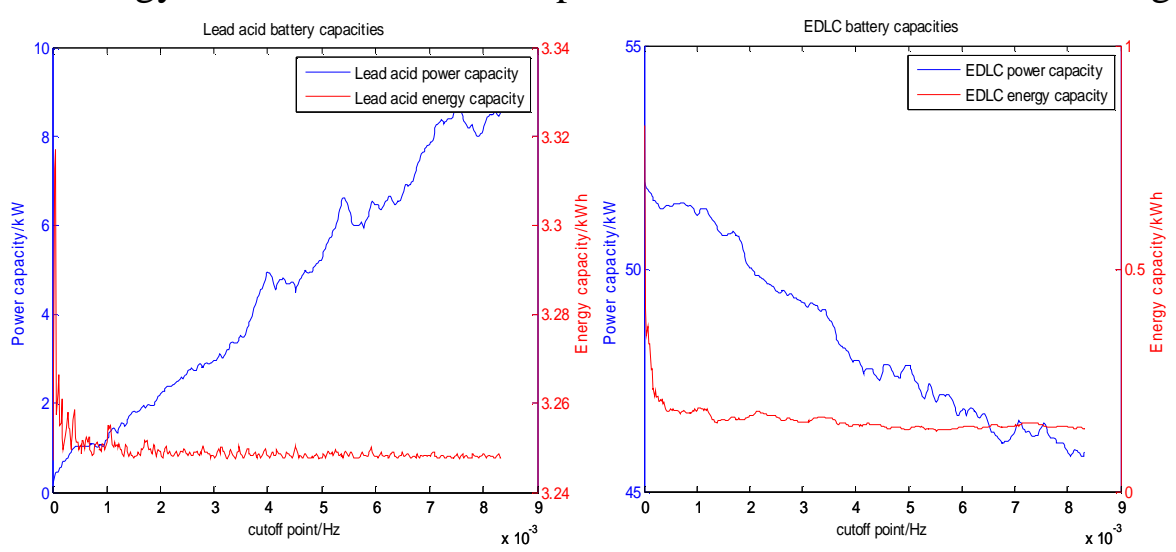

(1) lead acid battery+EDLC
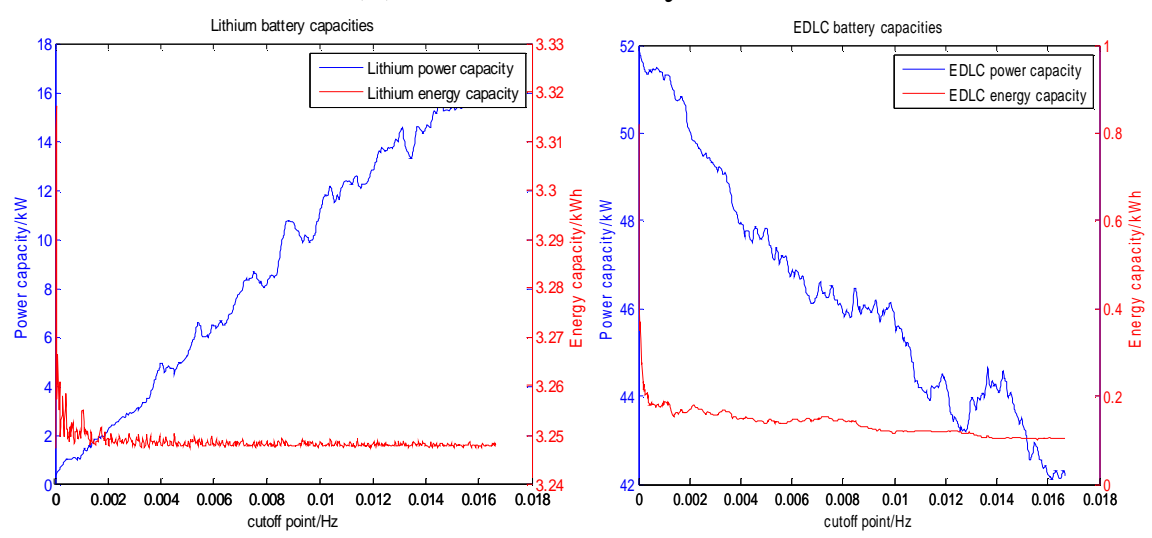

(2) lithium battery+EDLC

Fig. 3. ES capacities under different cutoff points

In Fig. 3, blue lines show the power capacity of each ES, red lines show the energy capacity of each ES. With the cutoff points moving toward right, the power smoothing requirement for long-term ES like lead acid and lithium battery increase, and requirement for EDLC decrease. Thus the calculated power capacities of lead acid and lithium battery will increase while EDLC calculated power capacity decrease when cutoff points move toward right. That's why blue lines in the left figures go up while in the right figures go down.

Since the energy capacities are obtained from the integration of balancing powers, they don't have obvious upward or downward tendencies in this selected worse case. Even though red lines in 
these figures drop dramatically under very low frequencies, there is no significant change in their values, which represent ES energy capacities when cutoff points move. Thus the value of red line can be seen as a constant. Also, Because of the power fluctuation in balancing powers, these capacities will not always go up or go down.

Then ESS total costs under different cutoff points can be calculated. Their tendency curves are shown in Fig. 4,

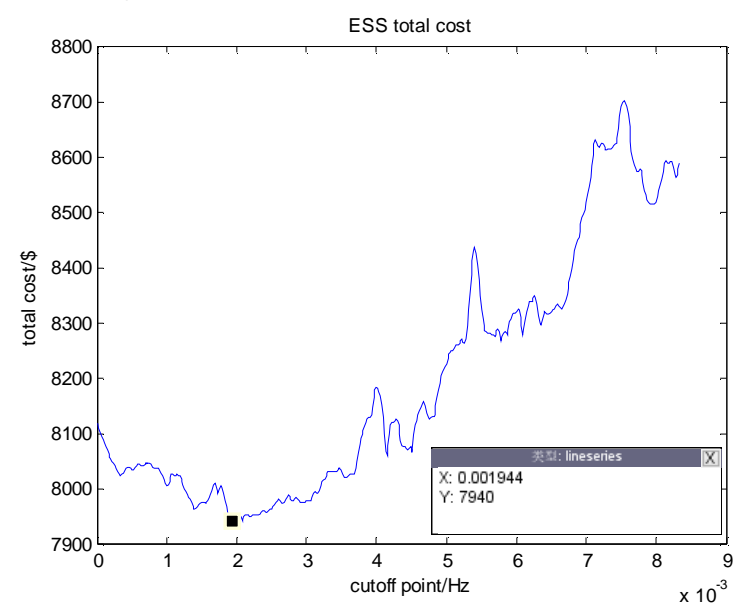

(1) lead acid battery+EDLC

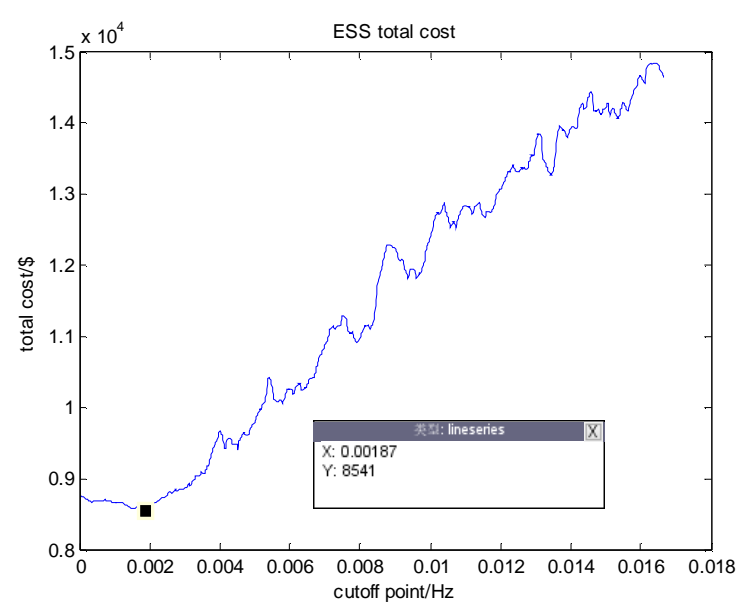

(2) lithium battery+EDLC

Fig. 4. ESS total costs under different cutoff points

In Fig. 4, When cutoff points moving within the long-term ES response frequency ranges, the total costs will not constantly increase or decrease because of the capacities in different combinations vary. Also, there is no obvious tendency of total cost because of the capacity modification. Even though the calculated power capacities and energy capacities of each ES have certain variation laws, when calculating system cost, they are modified as the rated capacities. That means the ES costs are sometimes obtained based on calculated power capacities, sometimes obtained based on energy capacities. The lowest point in each combination represents the minimum total cost of ESS in each combination.

According to the results, minimum total costs under different combinations are listed in Table 3 below:

Table 3. ESS calculated capacities

\begin{tabular}{ccccccc}
\hline \multirow{2}{*}{$\begin{array}{c}\text { Cutoff } \\
\text { point }(\mathrm{Hz})\end{array}$} & \multicolumn{2}{c}{ Lead acid } & \multicolumn{2}{c}{ Lithium } & \multicolumn{2}{c}{ EDLC } \\
\cline { 2 - 6 } & $\mathrm{P}(\mathrm{kW})$ & $\mathrm{E}(\mathrm{kWh})$ & $\mathrm{P}(\mathrm{kW})$ & $\mathrm{E}(\mathrm{kWh})$ & $\mathrm{P}(\mathrm{kW})$ & $\mathrm{E}(\mathrm{kWh})$ \\
\hline 0.001944 & 2.10 & 3.25 & & & 50.14 & 0.17 \\
0.001870 & & & 1.95 & 3.25 & 50.44 & 0.16 \\
\hline
\end{tabular}

Due to the fact that for each one ES on the market, the ratio of its rated power capacity and rated energy capacity is a constant value which equals to the ratio of unit energy price and unit power price. To meet both power and energy smoothing requiremnets, sometimes one of ES capacities needs to be oversized. Thus the calaculated ES power capacities and energy capacities are modified and listed in Table 4.

Table 4. ESS rated capacities and system total costs

\begin{tabular}{|c|c|c|c|c|c|c|c|}
\hline \multirow{2}{*}{$\begin{array}{c}\text { Cutoff } \\
\text { point }(\mathrm{Hz})\end{array}$} & \multicolumn{2}{|c|}{ Lead acid } & \multicolumn{2}{|c|}{ Lithium } & \multicolumn{2}{|c|}{ EDLC } & \multirow{2}{*}{$\begin{array}{l}\text { Minimum } \\
\text { cost }(\$)\end{array}$} \\
\hline & $\mathrm{P}(\mathrm{kW})$ & $\mathrm{E}(\mathrm{kWh})$ & $\mathrm{P}(\mathrm{kW})$ & $\mathrm{E}(\mathrm{kWh})$ & $P(k W)$ & $\mathrm{E}(\mathrm{kWh})$ & \\
\hline 0.001944 & 2.10 & 4.20 & & & 50.14 & 1.88 & 7940 \\
\hline 0.001870 & & & 1.95 & 3.25 & 50.44 & 1.89 & 8541 \\
\hline
\end{tabular}

Apparently, system with combination of lead acid battery and EDLC has the minimum total cost, which is $\$ 7940$ with the optimal cutoff point at $0.001944 \mathrm{~Hz}$. 


\section{Conclusion}

This paper proposed a sizing method for hybrid ESS based on frequency analysis to effectively smooth the power fluctuation under different frequencies as well as lower system total cost. Two combinations, which are short-term ES EDLC with long-term ES lead acid battery, and short-term ES EDLC with long-term ES lithium battery, are analyzed. Cutoff points of each combination is determined based on long-term ES response frequencies. Then, high pass and low pass FFT filtering are respectively conducted in frequency domain under different cutoff points based on a worst case scenario to calculate power capacities and energy capacities for each ES, as well as system total cost under each cutoff point. Also, factors like SOC and rated capacity modification are considered to make the design more reasonable and practical. Finally, a best hybrid ESS that is able to smooth out both power and energy fluctuations with lowest system total cost is determined to meet both power and energy smoothing requirements.

\section{Acknowledgements}

This work is supported by State Key Laboratory of Power Transmission Equipment \& System Security and New Technology (No. 2007DA10512713301) and the Fundamental Research Funds for the Central Universities(No. CDJZR12150024), Chongqing University, China.

\section{References}

[1] Hongxin J, Yang F, Yu Z, et al. Design of hybrid energy storage control system for wind farms based on flow battery and electric double-layer capacitor[C]/Power and Energy Engineering Conference (APPEEC), 2010 Asia-Pacific. IEEE, 1-6. (2010)

[2] Seniyu Tomonobu, Datta Manoj,Yona Atsushi Kim. A control method for small utility connected large $P V$ system to reduce frequency deviation using a minimal-order observer[J]. IEEE Trans Energy Covers, 24(2): 520-528. (2009)

[3] Electrical energy storage: white paper. Technical report. Prepared by electrical energy storage project team. International Electrotechnical Commission (IEC), Published December, (2011)

[4] Kelin Y, Ruiwen H, Haoming L, Control method of ESS in PV system to smooth the output power fluctuation, Electric Power Demand Side Management [J]. vol. 17, no. 2, pp. 17-21. (2015)

[5] Alvarado F L. Spectral analysis of energy-constrained reserves[C]//System Sciences, 2002. HICSS. Proceedings of the 35th Annual Hawaii International Conference on. IEEE, 749-756. (2002)

[6] Carnegie R, Gotham D, Nderitu D, et al. Utility scale energy storage systems[J]. State Utility Forecasting Group. Purdue University, (2013)

[7] Li B, Chen S, Liang S Y. A Suitable Method of Energy Storage Capacity Optimization Based on DFT for BIPV[C]//Applied Mechanics and Materials. 548: 901-909. (2014)

[8] Information on http://batteryplusforlife.com/research.html

[9] Makarov Y V, Du P, Kintner-Meyer M C W, et al. Sizing energy storage to accommodate high penetration of variable energy resources[J]. Sustainable Energy, IEEE Transactions on, 3(1): 34-40. (2012)

[10]Information on https://en.wikipedia.org/wiki/State_of_charge 